\title{
Stimulating Content Knowledge Learning of Intermediate Calculus through Active Technology-Based Learning Strategy
}

\author{
Sirak Tsegaye Yimer ${ }^{1 *}$ \\ ${ }^{1}$ Ambo University, College of Natural and Computational Sciences, Mathematics Department, Ambo, Oromia, ETHIOPIA
}

Received 7 April 2020 • Accepted 8 September 2020

\begin{abstract}
The purpose of the study was to explore whether learners' conceptual knowledge (CK) or procedural knowledge (PK) understanding of calculus using the stimulus of active technologybased learning strategy better influence their content knowledge (COK) development. The quantitative methods were used in a quasi-experimental design. CK, PK and COK achievement scores were sources used for data collected from 150 samples. Data analysis employed descriptive statistics conducting an independent samples t-test and a Two-Way ANOVA for repeated measures. The findings reveal that the use of the active learning interventions that heavily borrows and utilizes technology substantially stimulated experimental group (EG) to immensely raise their CK attainment as compared to PK development. The COK understanding was also significantly enhanced as a result of EG learners outperformed on CK. Consequently, the researcher suggests professional development for educators empowering them with such knowledge and skills involved in the active jigsaw co-operative method and GeoGebra learning strategy (JCLGS) that will influence classroom practices. This influence will then translate to learners' interests and positive attitudes towards calculus.
\end{abstract}

Keywords: active learning, intermediate calculus, content knowledge, technology-based learning

\section{INTRODUCTION}

For the first time, learners have come to learn calculus through their intuition in preparatory/upper secondary schools using the new mathematics curriculum in Ethiopia. An indispensable and a formal calculus course available for their higher learning which bridges secondary school and advanced university mathematics is intermediate calculus. Intermediate calculus course is one of a fundamental mathematics courses offered for the first year degree program learners enrolled in the Mathematics, Physics, Chemistry, and Statistics departments during their freshman study in the College of Natural and Computational Sciences of two Ethiopian public universities (Yimer \& Feza, 2019). Technology and engineering learners have also taken this same course with the addition of some other topics as Applied Mathematics I. Basics of limits, continuity, derivatives, application of derivative, integral and application of integral of a function of one variable are involved in it. At the outset, limit of a function at a point/number needs to be formally defined that learners were expected intuitively explain it in their preparatory secondary school mathematics. There are also other limit notions like existence of limit of a function at a point, left-and right-hand limit of a function at a point and so on which need to analogously be defined. At the tertiary level, the notion limit involves fixed and dynamic mathematical objects and ideas. Also, the ideas involved in all of them are wholly CK (concepts). By this reason, the learning of limit concept has been challenging for learners through the conventional lecture method which is often applied based on the theoretical model of delivering the subject matter under consideration. CK refers to knowledge of concepts with plenty of interrelationships, principles, and definitions as well as the understanding of the relationship among concepts in intermediate calculus (Chinnappan \& Forrester, 2014; Hiebert \& Lefevre, 1986; Star \& Stylianides, 2013). In the context of this study, learners' engagement on the developed learning activities focused more on CK as compared to PK using the JCLGS intervention had substantially benefited them to take a deep understanding of CK of calculus for means

(c) 2020 by the authors; licensee Modestum. This article is an open access article distributed under the terms and conditions of the Creative Commons Attribution License (http://creativecommons.org/licenses/by/4.0/).

$\square$ sirakbeliyu@gmail.com (*Correspondence) 


\section{Contribution to the literature}

- This study investigated and then realized that learners' CK development through active technologybased learning strategy has greatly influenced their COK development.

- The study creates educators awareness that the JCLGS can substantially enhance learners' CK and COK of calculus understanding to easily solve applied problems, and PK learning modestly.

- The study also adds to educators understanding on how they go beyond the traditional classroom instructional practices by combining technology with active learning strategy in the teaching and learning of calculus in particular and mathematics and science in general.

of easily solving applied problems as well as all about subject matter knowledge. This was achieved through going beyond the philosophy of teaching oriented to the theoretical mode of delivery by traditional lecture method emphasized on the transmission of PK to passive receivers to a classroom practices which were entirely collaborative, socially interactive and hands on experiences learning environment with the aid of GeoGebra that favoured learners to be active participants. However, the use of conventional lecture method has been more oriented to the teaching of PK (procedures) included in the remaining topics of limit in particular and intermediate calculus in general as indicated in most mathematics education research literatures reviewed as compared to $\mathrm{CK}$ for which learners were not successful on the overall subject matter and application knowledge of calculus development. Procedural knowledge (PK) is defined as knowledge of procedures or algorithms in intermediate calculus such as rules, algorithms (finite set of steps), routines, formulas and simple notations used in problem-solving (Chinnappan \& Forrester, 2014; Hiebert \& Lefevre, 1986; Star \& Stylianides, 2013). Mathematical education research communities viewed CK as deep knowledge and PK as superficial knowledge which has computational nature executed as now and then actions. COK refers to knowledge which is comprised of CK and PK as well as application knowledge in any given lesson and problem or the whole subject matter knowledge of intermediate calculus (Ball, Thames, \& Phelps, 2008).

The understanding of the notions continuity, derivative and integral in intermediate calculus entirely rely on learners effort that they have shown in understanding all about limit. This means if learners have not adequately understood the limit notion, it is often unlikely that they will learn better the notions continuity, derivative and integral. The unfavourable learning situation in turn lead learners not appropriately address the application part of derivative and integral as well. Especially, the application of derivative and integral is a very essential aspect for technology and engineering students. More learning power is expected from them to understand $\mathrm{CK}, \mathrm{PK}, \mathrm{COK}$ and the use of intermediate calculus in their daily life. Intermediate calculus is a very fundamental course for them in order to fruitfully acquire the notions in Applied Mathematics
II and III and the study of their field of specialization. Mostly learners' CK and COK gap in intermediate calculus and negative attitude exhibited towards it produced through the convention lecture method in classroom instructional setting has resulted in learning phobia for advanced university mathematics courses. This is an indicator for educational stakeholders to make an effort in transforming this unfavourable learning environment for intermediate calculus into favourable one in which learners have interest and enjoy it for successfully accomplishing advanced mathematics learning outcomes and cognitive development. In conclusion, intermediate calculus course is compulsory, central and very pertinent course that requires special attention first year undergraduate STEM and social science disciplines like business and economics learners to qualify for their degree in the program of study worldwide (Sebsibe \& Feza, 2019; Yimer \& Feza, 2019). Yimer and Feza (2019) also argue that calculus diverse ideas have potential to define and model problems that involve change in real life situations. Boz yaman (2019); Sebsibe and Feza (2019) confirms this argument by stating that intermediate calculus is an introductory course of making sense of real life situations to learners that are science and engineer oriented through mathematics.

However, identifying, understanding and selecting appropriate innovative teaching and learning models which are capable of enhancing learners' COK development of calculus by their initiation has been a challenge for educators (Yurniwati \& Soleh, 2019). Thus, the limited knowledge of the proposed strategy in this study observed in educators is a challenge as most of them have often engaged using the traditional method of teaching calculus at the tertiary level. The JCLGS was devised to increase learners' engagement as learners' engagement is linked with their cognitive development and learning outcomes (Ma, Han, Yang, \& Chen, 2015). As most mathematics education research literatures disclosed, the CK in calculus has challenged first year undergraduate STEM learners to a great extent through the traditional lecture method. For instance, as Bezuidenhout (2001); Engelbrecht, Harding, and Potgieter (2005); Kadijević (1999) reported, conventional lecture method has not addressed learners' learning challenge of calculus concepts rather it has entirely been 
used only for the purpose of imparting procedural knowledge which relatively demands lower order cognitive thinking. Similarly, Jaafar and Lin (2017); Kadijević (1999) argue that without knowing the applications, learners often get into rote memorizing of instrumental skills through solving procedural tasks that involve fully quantified objects. Because of this, the COK comprised of CK, PK and application knowledge of calculus (Ball, Thames, \& Phelps, 2008) attained by them has been tremendously decreasing. According to Huang (2011), the negative attitude exhibited by learners toward calculus was mainly influenced by teachers' repeated use of traditional instructional classroom practices. The learning of all mathematics courses offered in universities was not perceived by learners as normal as other courses. This is most likely due to lack of their prior CK in calculus and this in turn highly frustrate them to study about each advanced university mathematics courses.

As Sebsibe and Feza (2019) assessed, grade 12 natural science stream students in one administrative zone in Ethiopia have not been eliciting and probing the essence of CK in calculus, particularly limit of functions. The reason for this is learners have been learning calculus through their lower order cognitive thinking experiences acquired through traditional classroom instructional practices. Learners have spent much time to superficial knowledge learning in school mathematics which is generally computational requiring of them simple recalling to a finite set of steps. In Indonesia, Yurniwati and Soleh (2019) examined that prospective teachers' PK achievement was found to be higher than their CK in Geometry. The situation is quite the same in Zimbabwe in which most teacher-educators have shown lowerorder understanding to $\mathrm{CK}$ of the quadratic function (Mutambara, Tendere, \& Chagwiza, 2019). Globally, learners' CK learning difficulty in different areas of mathematics has been alarming. In connection to this, Sebsibe and Feza (2019); Mutambara, Tendere, and Chagwiza (2019) explored learners' mental construction of calculus and quadratic function concepts using actionprocess-object-schema (APOS) theory and then found they were at a lowest action/process stage of concept understanding. This bears to mind educators to go beyond the traditional classroom instructional practices. In support of this idea, Sebsibe and Feza (2019), Othman, Tarmuji, and Hilmi (2017) notified educators to look for alternative learning models involving educational technology that help to stimulate learners' concept learning whenever they have access for it. Thus, the rationale of the study is to fill this knowledge gap and the need to investigate the possibilities of using the JCLGS for stimulating learners' COK learning of calculus.

\section{Specific Objectives}

This study aims to achieve the following:
- To explore COK development of learners in both the experimental and control groups,

- To examine the extent of the influence of EG learners' CK development on their COK improvement,

- To inspect the extent of the influence of EG learners' PK development on their COK improvement.

\section{Research Questions}

This study responds to the following research questions with the aim of achieving its specific objectives:

- Does the JCLGS have influence on learners' COK development of calculus?

- To what extent EG learners' CK development influences their COK attainment?

- To what extent EG learners' PK development influences their COK accomplishment?

\section{Hypotheses}

The research questions of the study can equivalently be expressed in hypothetical statements as follows.

Null hypothesis

$\mathrm{H}_{01}$ : Learners $\mathrm{CK}$ development of calculus through JCLGS has the same influence as PK development on their COK improvement.

Alternative hypothesis

$\mathrm{H}_{11}$ : Learners $\mathrm{CK}$ development of calculus through JCLGS has better influence than PK development on their COK improvement.

\section{LITERATURE REVIEW}

\section{Conceptual Review}

\section{Conceptual Knowledge (CK) and Procedural Knowledge (PK)}

Many scholars/educators like Rittle-Johnson and Alibali (1999); Haapasalo and Kadijevich (2000); RittleJohnson, Siegler, and Alibali (2001); Rittle-Johnson and Siegler (1998) have often studied the terms CK and PK concurrently. However, they have not yet been able to delineated clear-cut distinction and relation between them since today. They rather conceived and applied them in the context and purpose of their research study. As to the researcher's understanding and stance, CK is deeper in depth and breadth for any given mathematical knowledge. PK is a superficial/surface level knowledge. Mathematical education research communities have viewed CK as knowledge quality while the psychology research communities have perceived it as a knowledge type (Star \& Stylianides, 2013). According to Star (2005), knowledge quality refers to the way that something is 
known-essentially and how well it is understood while knowledge type merely refers to "what is known." The framework set by mathematics education researchers revealed that $\mathrm{CK}$ of mathematics can be known deeply or superficially or something between them. Star and Stylianides (2013) refer to CK as mathematical knowledge involving principles and definitions. Similarly, Chinnappan and Forrester (2014) refer to it the knowledge that deals with understanding the relationships among mathematical objects. Thus, learners, instructors, researchers, curriculum developers and policymakers need to take a closer look at those features of CK requiring them some sort of abstract thinking. In accomplishing their educational mission, they should endeavour to make in-depth understanding rather than merely rote memorizing it. The researcher would like to bear in mind that CK was dealt deeply in this study rather than using it superficially. That is, more emphasis was given to the use of one of Skemp's levels of learning known as relational learning though Skemp identified two where the other is instrumental learning (Summit \& Rickards, 2013). This discussion reminds us that instrumental learning needs to be considered as the learning of PK while relational/logical learning should be viewed as the learning of CK (Jaafar \& Lin, 2017). If we are well-equipped with the attributes of different mathematical knowledge, then we will become alert and skilful in selecting the appropriate teaching/learning strategy that best suits for the learning of any given mathematics lesson.

PK is the other most crucial quality or type of mathematical knowledge. As with CK, most mathematical education research community view $\mathrm{PK}$ as knowledge quality while the psychology research community perceive it as knowledge type (Star \& Stylianides, 2013). However, it is most often regarded as superficial or surface-level knowledge. Chinnappan and Forrester (2014); Star and Stylianides (2013) refer to PK as a mathematical knowledge of rules, routines, finite set of steps, symbols and notations used in problem-solving. This explanation completely agrees with the one stated in Summit and Rickards (2013) article that, PK refers to the ability to carry out procedures or steps in the learning of mathematical problems. It is also mentioned in this article that most often learners have been paying more attention to the instrumental/PK learning. According to Jaafar and Lin (2017), learners often assume as instrumental learning allows them to gain temporary knowledge in such a way that with good marks in tests or examinations could be easily obtained. Most instructors have been encouraging such learning approach through their pedagogy and assessment procedures. Pedagogical content knowledge (PCK) is advised to be internalized by instructors/teachers in the course of day-to-day learning and teaching activities in order to minimize this problem. PCK refers to the interconnection between the science of teaching/pedagogy and $\mathrm{COK}$ that teachers can represent in a learner-friendly manner (Ball et al., 2008). However, in Jaafar and Lin article, it recommended that educators should be devoted to applying relational/CK learning in their future career. In this research project, PK was regarded as superficial knowledge as compared to CK. The other aspects of PK could also be highlighted along with $\mathrm{CK}$ as follows.

As most mathematics and science education and social science disciplines research literatures indicated, CK and PK have been yoked. Some of these researches asserted that $\mathrm{CK}$ needs to be initially instructed and then PK could be derived from it through the practice of problem-solving. Others claim PK should be gained first and then CK may be developed in learners' minds through abstraction. A few of them, for instance, Resnick (1987) stated that both CK and PK must be learned independently. Others described increase in CK in one's learning subsequently lead to an increase in PK and viceversa. Nevertheless, most research literatures state that instructors and learners have been emphasizing more on procedure-based instruction almost ignoring conceptbased instruction. This situation would have been taken as one of the reasons for the learning of calculus has become more challenging for learners. The problem was supposed to predominantly emanate from educators' way of presenting their lesson, which is usually the use of lecture method at the tertiary level. However, the researcher shares the view that concept-based instruction has to be encouraged more in the teaching/learning environment. As to these issues Haapasalo and Kadijevich (2000) indicated that there exist four distinct theoretical viewpoints. They are named concepts-first views, procedures-first views, inactivation view, and iterative view. However, this research study utilized iterative theory that most often describes the bi-directional relationship between $\mathrm{CK}$ and PK. Iterative theory is a theory of learning that states the bi-directional approach of learning to CK and PK emphasizing to the idea CK is the source to PK and vice versa and inseparable entities mutually enhanced in any given mathematics lesson learning environment. From its theme, we may note that this theory is flexible as to which knowledge is instructed first or the source to another. This reminds the researcher that either knowledge can be instructed first or the source of the other. Several researchers have succeeded in using this theory, researching on the two knowledge of mathematics lesson from elementary to tertiary level, for instance (Awang \& Zakaria, 2012; Mahir, 2009; Zulnaidi \& Zakaria, 2012).This research project is an intervention study that heavily borrows and utilizes technology intended to improve $\mathrm{COK}(\mathrm{CK}, \mathrm{PK}$ and application knowledge) of intermediate calculus. 


\section{Traditional Lecture Method of Instruction}

Yang and Deng (2005) defined the traditional lecture method (TLM) as the method that teachers impart knowledge, skill and attitude to their students orally and the students sit and listen passively and take short notes without taking their learning initiatives. In this research project, the traditional lecture method was used to teach intact comparison group learners. The researcher only made some sort of discussion with the instructors/data collectors on how to administer pre-test, post-test, and collect and organize data. The instructors with Master of Science Degree in Mathematics had 26 and 9 years experiences in teaching. When class begins, both instructors gave course outlines for their learners. After having taught for two weeks, they administered the pretest calculus diagnostic test for three hours. Thereafter, in the course of the lecture the two instructors supplied notes, worksheets, quizzes and mid-term test on each of the four chapters to their students. They also worked on the instructional tasks with learners following the usual trend of using traditional lectures in most universities of the world. The trend has been giving lectures by the lecturers and learners only take short notes and listen to them passively. The instructors also conducted tutorial classes to assist learners to work with worksheets. They also provided feedback on what learners attempted during the class participation, doing class work, home assignments, group work and tests. Two weeks before closing the academic semester, the instructors administered post-test similar to the pre-test items for three hours. Altogether, all the semester activities and tasks lasted twelve weeks of which four hours were used for lectures and two hours for tutorials per week, totally seventy hours. At the end of the semester, instructors corrected, classified, presented, and organized learners' calculus achievement test scores in collaboration with the researcher.

\section{Jigsaw Co-operative Method Combined with GeoGebra as Learning Strategy}

Co-operative learning strategy is a typical active learning strategy used to teach calculus in particular mathematics in general. The Jigsaw co-operative learning strategy is one type of co-operative learning strategy. According to Abed, Sameer, Kasim, and Othman (2019), Jigsaw co-operative learning strategy is defined as a small group learning strategy in which each member striving to be an 'expert' on any one given learning activity for their common goal success in the absence of competition. This Jigsaw method in the context of the current study was applied in the mathematics laboratory by forming Jigsaw group consisting of 4 or 5 learners which seems to be convenient in each laboratory class learning environment. It was aimed to examine whether experimental group (Jigsaw group) learners appropriately address the learning of the calculus learning activities on limits, continuity, derivative and integral of a function of one variable prepared by the researcher through the active Jigsaw co-operative learning strategy and GeoGebra facilitated by data collectors (instructors) or not. Thereafter, in each laboratory class better scorer student in the pre-test was assigned as chair person and a second student as secretary for each Jigsaw group. This is due to the more knowledge other (MKO) principle by (Vygotsky, 1980). Yimer and Feza (2019) refer to MKO as one who has better or best opinion, knowledge and skill in relative to others in their respective team learning in a given social learning environment of a certain subject/course. Following, one learning activity on a certain lesson was administered to one member in the home Jigsaw group. Expert (new) group was formed from home group members with the same learning activity. The expert groups were allowed to discuss together on one learning activity they are assigned for fifteen minutes. Next, members of the expert group come back to their respective home group. Each member then moved to share what he/she experienced in the expert group to the home group for ten minutes. The zone of proximal development (ZPD) principle by Vygotsky (1980) was employed for that purpose. Siyepu (2013, p.3) defined the ZPD as "the disparity between learners performance on learning tasks with and without other assistance." At the end of each laboratory class, each Jigsaw group went to work with GeoGebra in order to gain further clarification on that specific calculus concept which they were unclear with using GeoGebra's potential interactive environments by numerical, symbolical, algebraically, geometrical and graphical representations with the assistance of data collectors. All the aforementioned tasks were repeated cyclically in each laboratory class in the way shown Figure 2.

The JCLGS combining jigsaw method and GeoGebra as intervention was applied in the mathematics laboratory class to nurture experimental/Jigsaw group learners' in calculus learning. It focused more on CK development. The intervention was facilitated by the initial group instructors assigned for experimental group learners. One of the initial group instructors had taught for 24 years in high school, college and university. The other instructor had taught for 7 years only in the university. They were skilful with the free open-source mathematics software package, GeoGebra. The role of instructors had been guiding, helping, assisting, facilitating, and motivating learners to utilize their learning. They used the same course outline, hand-out, worksheets, pre- and post-test questions, quizzes, tests, and learning activities. In the course of the intervention, experimental group shared their experiences using JCLGS on the learning activities. Initial group instructors provided feedback on what learners attempted during class participation and in doing class work, homework/assignments, group work and tests. They 


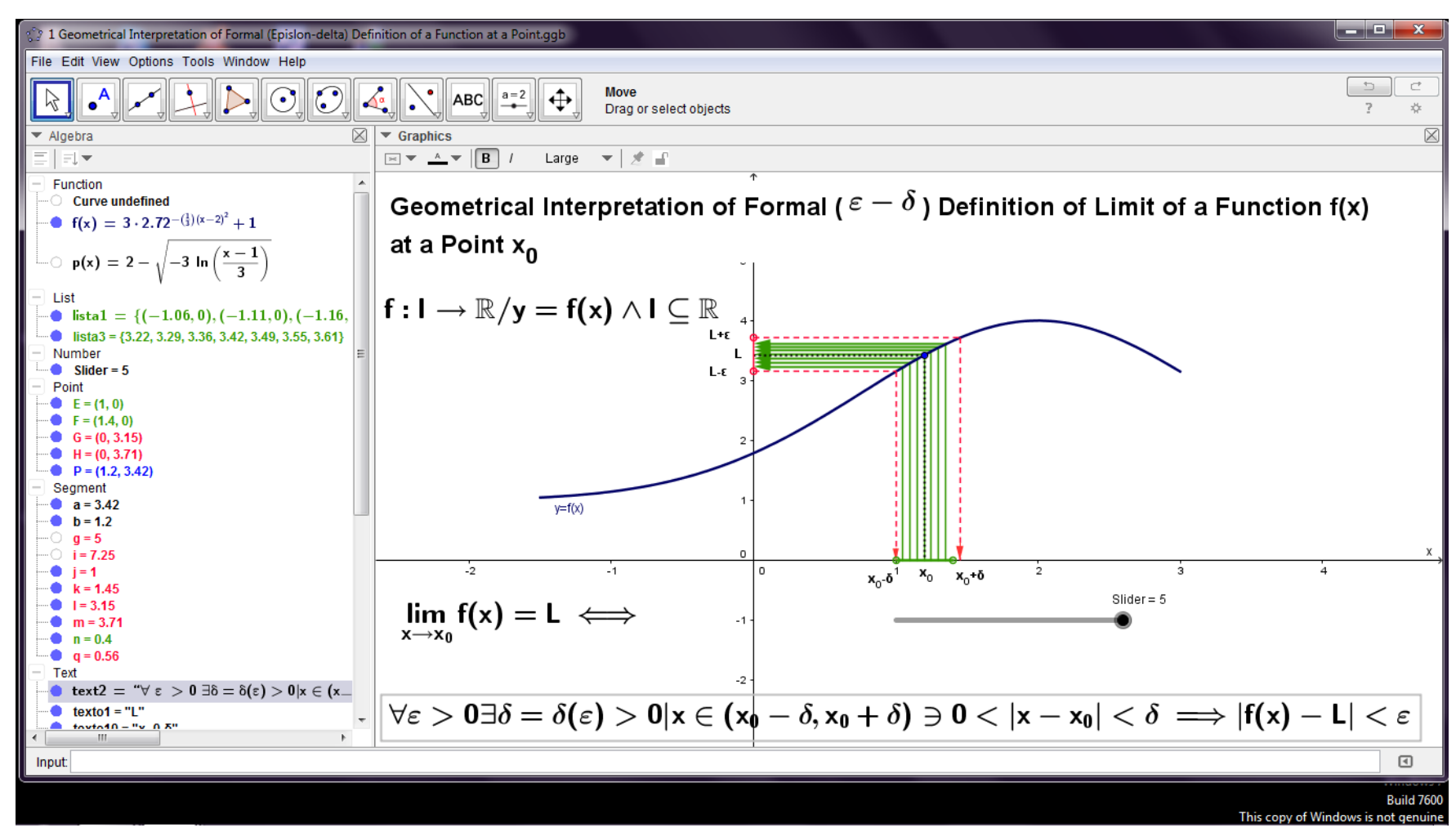

Figure 1. GeoGebra Applet on Formal Definition of Limit

also taught the intact experimental group using the lecture method in the mainstream class. Altogether, the experimental group learned calculus course for 4 hours in mainstream class and 2 hours in mathematics laboratory/tutorial class in a week.

In each mathematics laboratory class, the learning activities prepared by the researcher were discussed by the experimental/Jigsaw group interactively with each other and they eventually came to a consensus to what they agreed on. An example of a set of five learning activities on limits and continuity on which a discussion by each Jigsaw group was made at some day in the beginning of the intervention in the mathematics laboratory class is the following.

1. Formal $(\varepsilon-\delta)$ definition of limit of a function $\mathrm{f}(\mathrm{x})$ at a number (point) $\mathrm{x}_{0}$,

2. Formal $(\varepsilon-\delta)$ definition of one-sided limits (right-left limits),

3. Infinite limit and limit at infinity,

4. Formal $(\varepsilon-\delta)$ definition of continuous function $\mathrm{f}(\mathrm{x})$ at a number (point) $\mathrm{x}_{0}$ and

5. One-sided continuity.

At the outset, five home Jigsaw groups consisting of five learners were formed by data collectors. One learning activity was administered to a member. A new (expert) group was then formed from the home group members with all the same learning activities. The expert group were allowed to discuss on one learning activity for fifteen minutes by data collectors. Members of the expert group come back to their respective home group with five different activities. Each expert/ambassador explained what he/she grasped from the expert group to the home group for two minutes. During the discussion, each data collector acted as coach, guider, mentor, supporter and facilitator by making round observation and help for the activity for which learners were unclear and disagree with in their argument. If learners come across an abstract calculus concept, they would further visualize using symbolically, algebraically, geometrically, and graphically and calculus means representations with aid of applets constructed in advance, the distinct interfaces, input, algebra and graphics windows in GeoGebra. GeoGebra applet used to illustrate the geometrical interpretation of the formal $(\varepsilon-\delta)$ definition of limit of a function $f$ at a point/number $x_{0}$ that helped learners to understand this abstract definition is shown Figure 1.

The scheme of the intervention with Vygotsky's socio-cultural context learning theory generally look likes as shown Figure 2. 


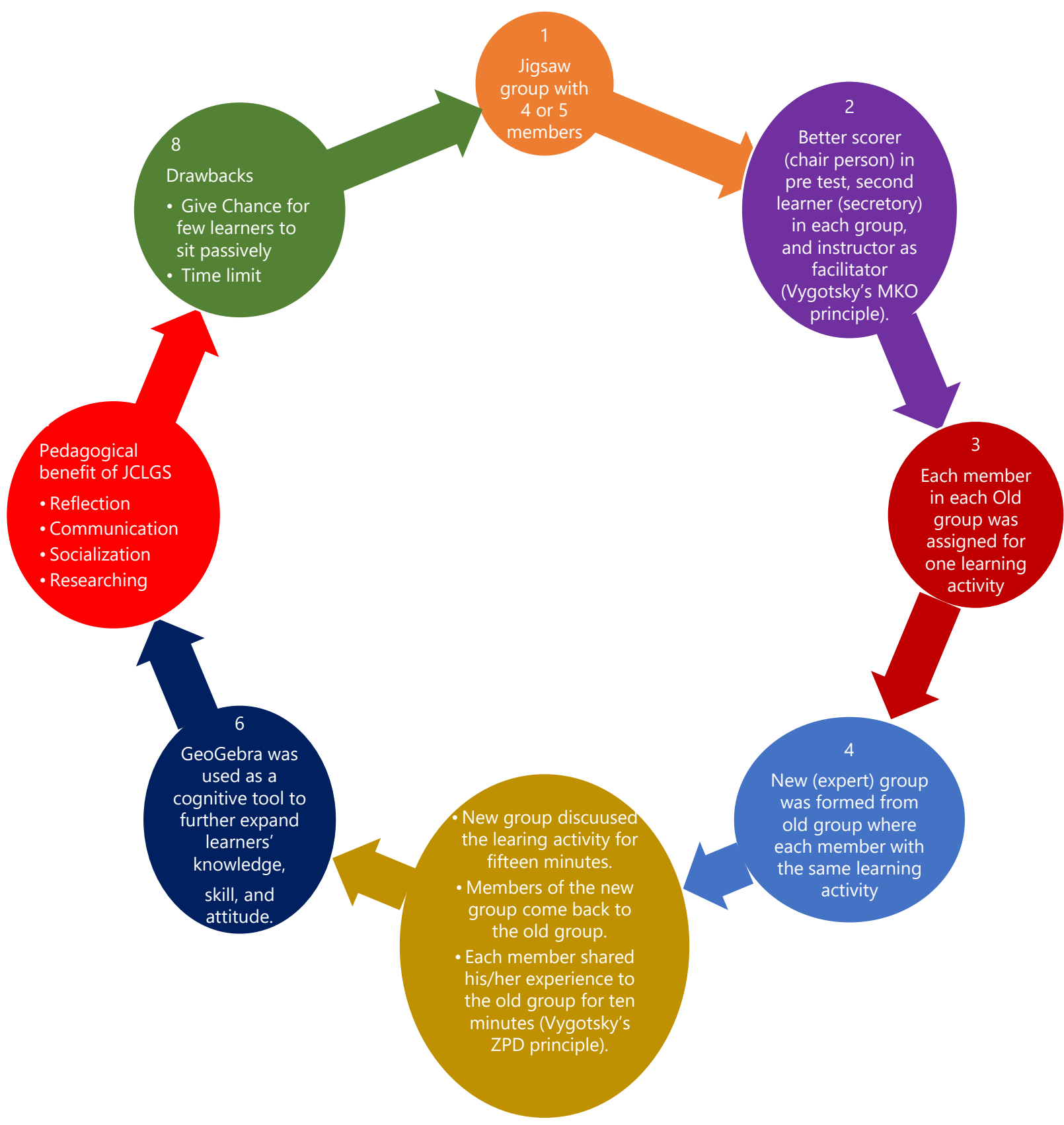

Figure 2. Scheme for the Process in JCLGS adapted from Orey (2010)

\section{Theoretical Framework}

This research project was an intervention study intended to improve learners' COK (CK, PK and application knowledge) of calculus. Rittle-Johnson and Siegler (1998) suggested that learners' CK and PK of mathematics can be improved through intervention experimental study. The JCLGS with Vygotsky's sociocultural context learning theory was used as stimulus in learners' calculus learning. Socio-cultural context learning theory highly emphasized on the importance of learners' interaction in the group and community in the context of their learning environment in the development of cognition and in the process of "making meaning" (Vygotsky, 1980; Wertsch, 1985). Wertsch was one of the propounders of Vygotsky's learning theory. Socio-cultural context learning theory was supposed pertinent in calculus learning activities by the stimulus of JCLGS learning environment to enhance learners' interest, attitude, performance and achievement. The JCLGS was the innovative learning strategy used in the intervention to verify that the learning activities prepared by the researcher address learners' styles of learning and interest. The socio-cultural context learning theory was also the one compatible with and more suitable for the technology integrated learning environment. The purpose of using this theory was to 


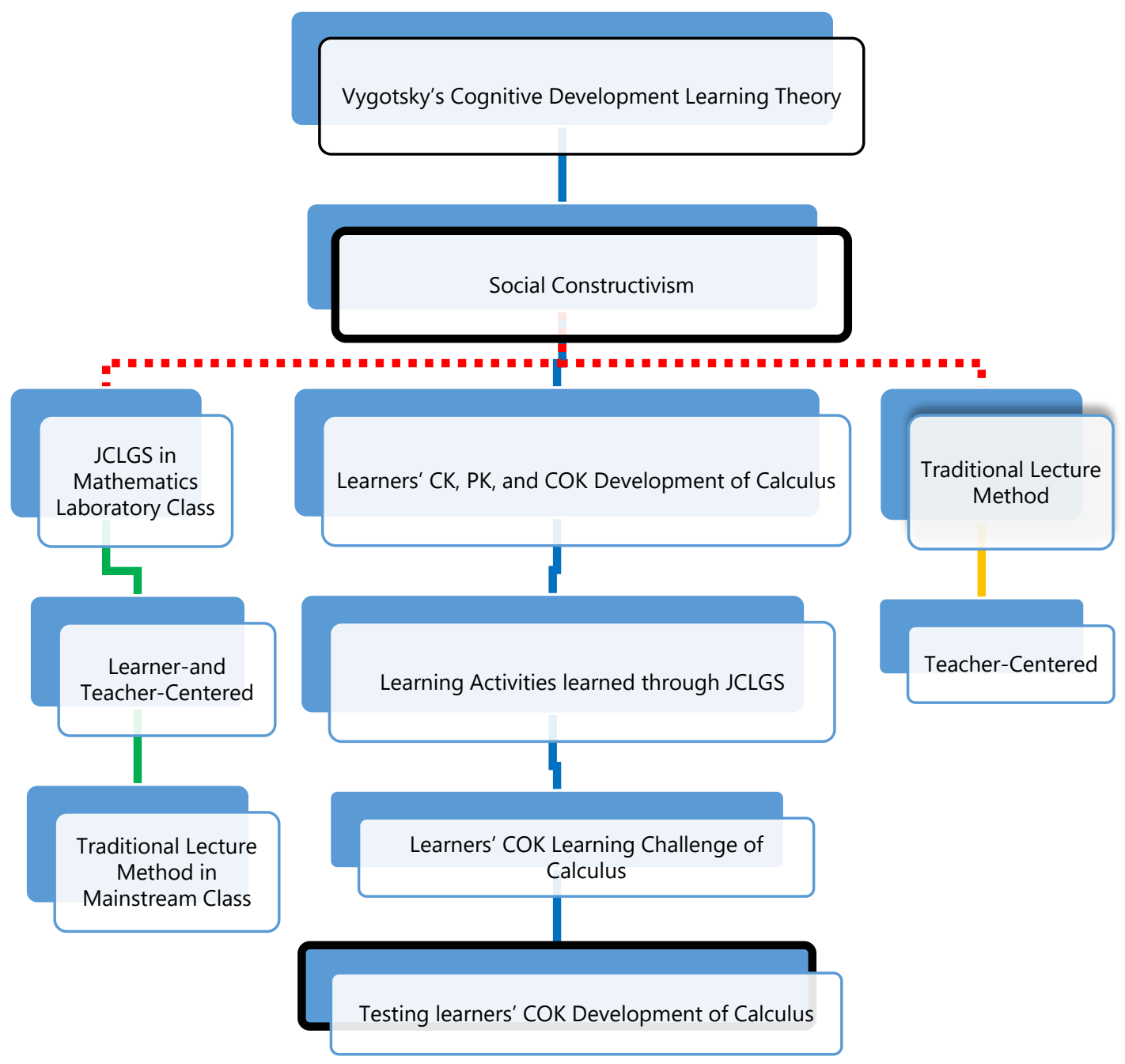

Captions

Expected strong relationship between the components in the Model.

-... Expected weak relationship between the components in the Model.

C Social constructivism learning theory highly involved in the development as well as implementation of the learning activities

Figure 3. Theoretical Framework adapted from Imenda (2014)

create a conducive and active interactive social circumstance and thereby to increase learners' capacity to attain and effect the desired cognitive development and learning outcomes. According to Amineh and Asl (2015), learners could employ it to inform peer group their previous experiences and knowledge, and the learning experiences gained through the existing interactive learning environment. Socio-cultural context learning theory can also assist each learner to provide meaning to the knowledge, skill and attitude which are being developed. This theory was applied through the JCLGS and lecture method as independent variables. Learners' calculus achievement test scores on CK, PK and COK were dependent variables. The theoretical framework is concisely depicted in Figure 3.

The findings had shown that the intervention with Vygotsky's social constructivism learning theory shown Figure 3 highly benefited learners' $\mathrm{CK}$ and COK development and modestly enhanced PK. From this finding, it can be concluded that learners CK performance had been highly influential to their COK development of intermediate calculus. Although the traditional lecture method also affected comparison group learners' CK, PK and COK development in the course of the study, the effect was incomparable to that of the intervention applied on the experimental group (EG). This situation reminds educators to go beyond the use of obsolete traditional lecture method and magnify the use of innovative pedagogies and strategies analogous to the active technology-based intervention with the social interactive learning environment in classroom instructional practices employed in the current study. 


\section{Empirical Review}

\section{Jigsaw co-operative learning strategy}

A summary of empirical results from a few reviewed research literatures in order to enable readers to have an overview idea about the extent of the importance and influence of jigsaw co-operative method and GeoGebra on the learning of various courses is provided.

Dhage, Pawar, and Patil (2016) conducted a study on a sample of 20 engineering students and suggested that a research should be conducted to make a comparison between the effect of the traditional lecture method and active learning method in students learning. Such an active learning method that should come into comparison with the passive lecture method is the Jigsaw learning strategy. The aim is to create on learners' critical thinking and creativity and then help them to apply what they learned in their real-life. They also suggested that the traditional teaching method should be transformed into any active learning method. Othman et al. (2017) also forwarded a similar idea that innovative learning strategy must overtake the role of the conventional teaching and learning models in classroom instruction.

Gull and Shehzad (2015) carried-out a study to examine the effect of Jigsaw II method on students' achievement in the subject of Education. The sample size was 63 female students enrolled in grade 12 of a public college. The pre- and post-test control group quasiexperimental design was used. The data were analyzed using the paired sample t-test and independent samples t-test. The findings showed that there was a statistically significant difference between experimental and comparison groups in post-test scores. Students enrolled in the subject Education positively achieved by Jigsaw II method. The other co-operative learning strategy, namely STAD and TGT, used in this same study had also contributed for learners' success. Gull and Shehzad describe Jigsaw II method as a group instructional method typically involving two special groups named home and expert groups where home group efforts for their own learning on the available learning material and expert group responsible to share what they experienced on their learning material merely with essence of collaboration. According to Arends (1997), STAD stands for Student Team-Achievement Divisions which refers to a type of group learning approach in which members endeavour to learn to that lesson the teacher provide them until understanding of each member is ensured and their assessment scored individually and collectively and then on the basis of groups scores the one with highest score is identified as the winning group. TGT is an abbreviation for Teams-GamesTournament which refers to a group instructional technique under which there is a winning and losing (competition-collaboration) structures in the heterogeneous groups and they learn by playing multiple games using the available materials and eventually assessment is undertaken on the individual and group level for the purpose of identifying the winning or losing team (DeVries, 1974).

Sengul and Katranci (2012) conducted a research investigating the benefit of Jigsaw method on nineteen $6^{\text {th }}$ grade students in Kocaeli in three lessons of 'sets'. A qualitative paradigm was used. The data were descriptively analyzed. The results showed that students enjoyed and understood the subject matter in 'sets' learning using Jigsaw method

A research on the effect of Jigsaw co-operative learning strategy on the achievement, knowledge retention, and attitude toward this learning strategy of 80 final-year Vietnamese mathematics students was conducted by (Tran \& Lewis, 2012). The experimental and control groups were matched groups each with 40 students. The quasi-experimental design was used. The data were analyzed by ANOVA, ANCOVA, and MANOVA. The findings revealed that the experimental group perceived the Jigsaw method more co-operative and student-centered. The knowledge retention and achievement of the experimental group was significantly larger than the control group.

Gambari and Yusuf (2016) conducted a comparative study that compares the effect of computer-assisted Jigsaw II and individualized computer instruction on senior secondary school physics students. A nonequivalent and non- randomized pre-and post-test quasi-experimental design was used. Purposive sampling technique was used to select eighty research participants from two intact classes. The data were analyzed using ANCOVA and Scheffe's test. The findings reveal that students taught with computerassisted Jigsaw II were better performed and retained physics concepts longer than those taught with individualized computer instruction. This implies the role of Jigsaw II method in learners' physics concept learning was paramount.

Abed et al. (2019) examined the effect of the predictive power of Jigsaw strategy on low proficient students' proficiency in mathematics and on their achievement of grade-two students enrolled in 20172018. The sample size was 80 in both the experimental and comparison groups. Explanatory research design was used. Data were analyzed by an independent samples t-test. The findings showed that the experimental group students better performed in mathematics than the control group. Experimental group students also changed their attitude positively towards mathematics lessons through Jigsaw learning strategy.

\section{GeoGebra}

In this ever advancing digital world, mathematics software packages have played a multi-faceted role in 
education sphere of life. GeoGebra is one type of such mathematics software packages used for teaching and learning mathematics at all levels (http:/ / www.mediawiki.org). GeoGebra was employed in this intervention experimental study as a tool in the devised innovative learning strategy in learners' calculus learning. Many researchers obtained remarkable results that GeoGebra benefited for the successful attainment of students in different areas of mathematics. The empirical results available in some reviewed research literatures are evidence to that and stated as follows.

Saha, Ayub, and Tarmizi (2010) conducted their research to examine the effect of GeoGebra on learners' co-ordinate geometry achievement. Both experimental and control groups comprised 53 participants. The nonequivalent post-test only control group quasiexperimental design was used. Data were analyzed using an independent samples t-test. The findings showed that the experimental group taught with GeoGebra achieved better than the comparison group taught through the traditional teaching method.

Zakaria (2012) conducted a study to identify the effect of GeoGebra on high school learners' PK and CK of function in terms of their group and gender. The experimental group comprised 138 participants. The participants in the control group were 146. A nonequivalent pre- and post-test control group quasiexperimental design was used. Data were analyzed using T-test, One-Way ANOVA and Two-Way ANOVA. The results revealed that there is a statistically significant difference in learners' CK and PK achievement based on their group. The results also showed that there is no a statistically significant difference in learners' CK and PK achievement regarding gender.

\section{METHODOLOGY}

The study employed the post-positivist philosophy, deductive approach, intervention experiment, quantitative method, critical realist ontology (objectivist or constructionist or both) and empiricist or interpretive or both epistemology (Saunders, Lewis, \& Thornhill, 2009). As post-positivists share the view reflected by positivists, at the outset it is worth noting positivism. According to Castellan (2010); Yilmaz (2013), positivism is one of the schools of thought that believes physical and social reality exist independent of our senses. This perspective is most often recommended to be used in true or pure experimental methods (Gelo, 2012). It is not applicable in educational and social science research that mostly entertain people subjective judgements. By this reason, post-positivism was considered a well-suited outlook for the current study. Gelo (2012, p. 118) indicated that post-positivism is similar to positivism but "it still contemplates reality, but affirm that this is only imperfectly/probabilistically apprehensible." In other words, post-positivism refers to a belief that physical and social realities are not completely existed independent of our sense. Castellan (2010); Yilmaz (2013) were in support of this idea that the postpositivists cannot observe the world as outsiders, rather they consider themselves as part of it. In connection with this, ontology as a branch of philosophy refers to "the study of nature of reality" (Gelo, 2012; Gray, 2013; Saunders et al., 2009, p. 110). Critical realist ontology refers to a perspective to knowledge as something that could be discovered based on the raw data (realist/objectivist) or constructed by research data collectors and participants (constructionist) or both (Gelo, 2012). Critical realist ontology implies that no reality exists completely independent of our senses. Epistemology as a branch of philosophy refers to "the study of nature of knowledge" (Gelo, 2012; Gray, 2013; Saunders et al., 2009, p. 112). Since this research was an intervention experimental study (empiricist) based on the socio-cultural context learning theory, the knowledge developed by learners is the one constructed through social interaction with each other by giving meaning to knowledge being gained (interpretive) and with the surroundings in the designed learning environment. This bears us to mind learning is often social by its very nature. In terms of research processes, the deductive approach implies that the research should be undertaken with the intent of testing hypotheses/theories, rather than developing them. This means, the researcher needs to state a hypothesis/theory almost at the beginning of the proposal writing and then proceed with conducting data collection to test it. Finally, he/she should reflect on its confirmation or disconfirmation based on the inferential statistics results and analysis (Creswell \& Creswell, 2019).

\section{Research Design}

A non-equivalent pre-test and post-test comparison group quasi-experimental design was used. According to Morgan, Leech, Gloeckner, and Barrett (2012), the quasi-experimental design used in this study is also called repeated measures design. Morgan Leech, Gloeckner, and Barrett also described such design is common in longitudinal and intervention research. This research project is longitudinal as the data were gathered at two points in time for pre-and post-test session.

\section{Population of the Study}

The target population for the pilot and main study was the whole freshman undergraduate mathematics and science learners in two Ethiopian public universities who enrolled for calculus. The two public universities were quite similar in academic, administrative, geographical and demographic attributes, located west of Ethiopia, particularly west of Oromia. Despite this, intact learners in one of the two universities were taken as comparison group while those in the second 
Table 1. Table of Specification/Test Blue Print for Content Validity (Bloom's Taxonomy)

\begin{tabular}{|c|c|c|c|c|c|c|c|c|c|}
\hline \multirow[t]{3}{*}{ Topics } & \multicolumn{9}{|c|}{ Questions } \\
\hline & \multicolumn{3}{|c|}{ True-false } & \multicolumn{3}{|c|}{ Multiple-choice } & \multicolumn{3}{|c|}{ Work-out } \\
\hline & CK & PK & COK & CK & PK & COK & CK & PK & COK \\
\hline Limits & 4 & 3 & 7 & 6 & 7 & 13 & 1 & 1 & 2 \\
\hline Continuity & 5 & 1 & 5 & 8 & 2 & 9 & 2 & 1 & 3 \\
\hline Derivative & 11 & 4 & 11 & 9 & 7 & 15 & 2 & 2 & 4 \\
\hline Integral & 1 & - & 1 & - & 1 & 1 & - & 1 & 1 \\
\hline
\end{tabular}

university as experimental group at the outset of the intervention.

\section{Sampling Procedure}

The sample was drawn using a two-stage random sampling technique (Fraenkel \& Wallen, 2009). At the outset of the intervention, cluster random sampling was used to select randomly Statistics and Chemistry departments from the College of Natural and Computational Sciences. Based on intact group participants' age, gender and scores of Ethiopian University Entrance Certificate Examination (EUEE) and using the codes given to each participant in the collected data, lottery method was used to draw sample participants after data collection.

\section{Sample}

A sample of 16 male and 14 female participants was randomly drawn for pilot study from the 84 intact statistics learners sat for calculus diagnostic test of which ten were low, ten were medium and ten were high achievers. One hundred fifty were samples for the main study. The comparison group comprised 75 samples drawn from 103 chemistry and statistics learners in one of the two universities (30 females and 45 males). Their age ranges 18 to 25 . The remaining 75 samples (50 males and 25 females) made up the experimental group (EG) selected from 145 chemistry and statistics learners in the second university. Their age ranges 18 to 24 . The proportion of males to females in both groups was similar. The age range for both groups was nearly the same. Similarity of experimental groups in age and gender was important to control extraneous variables that equally bring rival explanations with that of the independent variable in using a quasi-experimental design (Fraenkel \& Wallen, 2009).

\section{Instrument}

CK, PK and COK of calculus classroom achievement test scores were sources used for data collection and presented in terms of multiple-choice and true-false (closed-ended), and work-out (open-ended) items.

\section{Validity and Reliability}

The concept of validity refers to that device used to estimate what the research instrument was intended to measure (Saunders et al., 2009). It is mainly of two types named internal and external validity. As this study was a comparative study, the internal validity is the appropriate procedure used to make sure to draw the appropriate inferences based on the data collected. Internal validity can be validated through three testing techniques named content related, construct related and criterion-related evidence (Fraenkel \& Wallen, 2009). Content validity is the one that most applied in the achievement test. Accordingly, the content/face validity of the pilot test was evaluated by three subject experts based on such a benchmark points as the adequacy of sample questions and whether the proposed objectives of the research was in line with the syllabus or not. Finally, the researcher corrected some of the comments forwarded by course experts. The table of specification for content validity is depicted in Table 1.

Reliability is the other important device which complements validity used to assess stability of an instrument and the degree of consistency of participants responses (Fraenkel \& Wallen, 2009). It is of three types such as test-retest, equivalent form and internal consistency methods (Fraenkel \& Wallen, 2009). According to Fraenkel and Wallen (2009), the internal consistency reliability method introduces a small standard error of measurement. Despite that, the reliability of the pilot test was estimated by the internal consistency method due to lack of resources. The difficulty level of an item (P), discrimination index (D), point-biserial coefficient $\left(\mathrm{r}_{\mathrm{pbi}}\right)$ and reliability coefficient index $\left(\mathrm{r}_{\text {test }}\right)$ Ding and Beichner (2009); Kiliyanni and Sivaraman (2016) were the four-item analysis indices used. This was to examine the true-false items and multiple-choice to improve their quality and accuracy for the main study. Estimates for $P=0.72, D=0.38$, $\mathrm{r}_{\mathrm{pbi}}=0.26$ and $\mathrm{r}_{\text {test }}=0.7$ for the true-false test items were acceptable values (Boopathiraj \& Challamani, 2013; Ding \& Beichner, 2009). Similarly, estimates for $\mathrm{P}=0.45$, $\mathrm{D}=0.61, \mathrm{r}_{\mathrm{pbi}}=0.46$ and $\mathrm{r}_{\mathrm{test}}=0.9$ for the multiple-choice items were also acceptable. The inter-rater reliability for the work-out items was measured by Pearson Product Moment Correlation, r (average) $=.985$ (Liao, Hunt, \& Chen, 2010) and the inter-rater agreement reliability [intra-class correlation coefficient, ICC (average)=.983] on single measure and are of very high values (Graham, Milanowski, \& Miller, 2012). 
Table 2. Descriptive statistics for Pre-and Post-test on CK, PK and COK Scores

\begin{tabular}{lccccccc}
\hline & & & \multicolumn{3}{c}{ Statistics } \\
\hline Variable & Group & Valid & Missing & Skewness & Kurtosis & Skewness \\
\hline CK & EG & 75 & 0 & .109 & -.586 & -.296 & -.822 \\
& CG & 75 & 0 & .642 & -.476 & .164 & -.369 \\
PK & EG & 75 & 0 & .579 & .063 & -.268 & -.893 \\
& CG & 75 & 0 & .600 & 1.069 & .596 & .367 \\
COK & EG & 75 & 0 & .268 & -.553 & -.367 & -.801 \\
& CG & 75 & 0 & .075 & -.403 & .019 & .361 \\
\hline
\end{tabular}

Note. EG=Experimental Group, $\mathrm{CG}=$ Comparison Group

\section{Data Collection and Preparation Procedures}

Data-collection for the main study was conducted in the pre-test \& post-test sessions on the calculus classroom achievement test. The calculus classroom achievement test consisted of three parts with 55 questions. The first part had 20 true/false, the second part 30 multiple-choice and the third part 5 work-out items. Each part had got items used to measure three dependent variables such as learners' CK, PK and COK scores. Part one consisted of 15 CK, 2 PK and 20 COK items. Part two had 26 CK, 18 PK and 60 COK items. Part three consisted of $4 \mathrm{CK}, 8 \mathrm{PK}$ and $20 \mathrm{COK}$ items. The distribution of items for each part of the tests was based on the researcher intent to assess how much learners had given attention to their CK learning through JCLGS in the mathematics laboratory class as traditional lecture method had been favouring learners' PK development indicated in most empirical results reviewed. Overall, the desired data on the classroom achievement test were obtained based on CK, PK and COK scores, respectively out of $45 \%, 28 \%$ and $100 \%$. Learners' responses on the first and second part were scored by the data collectors using the generated answer key by the researcher and instructors (data collectors). The average scores on the responses rated by the researcher and data collectors were calculated on part three. The researcher and data collectors had carried-out the correction by taking into consideration the purpose of the study. At the end of the day, the researcher entered the organized data into SPSS 23.

\section{DATA ANALYSIS}

When data are collected over a semester in academic year program, Saunders et al. (2009) suggested that an independent samples t-test and a Two Way ANOVA for repeated measures are the suitable and widely used parametric test statistics to test changes over time. One continuous dependent variable, one nominal variable (instructional method/independent variable), two experimental conditions/factors and two different groups of participants involved in this study could also be taken as the other factors for utilizing these inferential statistical tools (Kandemir \& Demirbağ-Keskin, 2019). According to Cohen, Manion, and Morrison (2007), the collected data should meet the requirement of the assumptions underlying in an independent samples ttest and a Two Way ANOVA for repeated measures. The $99 \%(\alpha=0.01)$ level of statistical significance was employed because of the care and attention given to the intervention by the researcher, data collectors and research participants. However, the 95\% level of statistical significance $(\alpha=0.05)$ was the one most commonly and widely used in mathematics education research. The remaining assumptions could be tested as follows.

\section{Statistical Results, Findings and Interpretation}

At the outset, whether the collected data met normal distribution, homogeneity of variances, randomly selected sample unit, scores independent of each other on the dependent variable, and data measured at least at interval level or not needs to be assessed as follows (Field, 2009). Each unit was randomly drawn from the population from which the sample was taken for both groups. The collected data were measured at a ratioscale that represented learners' $\mathrm{CK}, \mathrm{PK}$ and $\mathrm{COK}$ achievement scores. According to Field (2009); Pallant (2010), the normality for each pair of data set can be tested using the skewness and kurtosis values as well as the significance value (sig.) based on KolmogorovSmirnov test while homogeneity of variances by Levene's test. The normality of a distribution can be decided by significance value more than 0.05 (significance) while non-normality by significance value less than 0.05 (non-significance). As Field (2009); Green and Salkind (2005) explored, D denotes the KolmogorovSmirnov test statistic reported with the degree of freedom (df) and significance level (sig.). Similarly, F denotes Levene's test reported with a degree of freedom as $F\left(\mathrm{df}_{1}, \mathrm{df}_{2}\right)=$ value, sig. The skewness value, kurtosis value, mean and standard deviation for pre-test on dependent variables CK, PK and COK scores are displayed in Table 2.

Each skewness and kurtosis values shown in Table 2 for the distribution of EG and CG on pre-test and posttest CK, PK and COK scores were in support of the normality as these values were relatively close to zero (Field, 2009). The kurtosis value (1.069) for EG on pretest PK cannot be viewed as a problem for analysis because the sample size was large which is greater than 
Table 3. Kolmogorov-Smirnov Test for Pre-and Post-test on CK, PK and COK Scores

\begin{tabular}{|c|c|c|c|c|c|c|c|}
\hline & & \multirow[b]{3}{*}{ Group } & \multirow[b]{3}{*}{$\mathrm{df}$} & \multicolumn{4}{|c|}{ Statistics } \\
\hline & \multirow[b]{2}{*}{ Variable } & & & \multicolumn{2}{|c|}{ Pre-test } & \multicolumn{2}{|c|}{ Post-test } \\
\hline & & & & Statistic & Sig. & Statistic & Sig. \\
\hline \multirow[t]{6}{*}{ Pre-test } & CK & EG & 75 & .083 & $.200^{*}$ & .986 & .553 \\
\hline & & CG & 75 & .137 & .001 & .943 & .002 \\
\hline & PK & EG & 75 & .136 & .001 & .946 & .005 \\
\hline & & CG & 75 & .121 & .008 & .953 & .008 \\
\hline & $\mathrm{COK}$ & EG & 75 & .103 & .048 & .978 & .206 \\
\hline & & CG & 75 & .053 & $.200^{*}$ & .990 & .798 \\
\hline \multirow[t]{6}{*}{ Post-test } & CK & EG & 75 & .075 & $.200^{*}$ & .961 & .021 \\
\hline & & CG & 75 & .070 & $.200^{*}$ & .987 & .627 \\
\hline & PK & EG & 75 & .110 & .025 & .952 & .007 \\
\hline & & CG & 75 & .133 & .002 & .959 & .016 \\
\hline & $\mathrm{COK}$ & EG & 75 & .107 & .035 & .952 & .007 \\
\hline & & CG & 75 & .065 & $.200^{*}$ & .991 & .874 \\
\hline
\end{tabular}

*. This is a lower bound of true significance. a. Lilliefors Significance Correction

Table 4. Independent-samples t-test for Pre-and Post-test on CK, PK and COK Scores

\begin{tabular}{|c|c|c|c|c|c|c|c|c|c|c|c|}
\hline & \multicolumn{11}{|c|}{ Levene's Test } \\
\hline & Variable & Group & $\mathrm{n}$ & $\mathrm{M}$ & SD & $\mathrm{F}$ & Sig. & $\mathrm{df}$ & $t$ & $\mathrm{p}$ & Eta squared \\
\hline \multirow[t]{6}{*}{ Pre-test } & CK & EG & 75 & 13.907 & 4.606 & \multirow{2}{*}{.875} & \multirow{2}{*}{.351} & \multirow{2}{*}{148} & \multirow{2}{*}{.149} & \multirow{2}{*}{.882} & \multirow{2}{*}{.00014} \\
\hline & & CG & 75 & 13.800 & 4.142 & & & & & & \\
\hline & PK & EG & 75 & 7.720 & 2.560 & \multirow{2}{*}{.026} & \multirow{2}{*}{.872} & \multirow{2}{*}{148} & \multirow{2}{*}{.345} & \multirow{2}{*}{.730} & \multirow{2}{*}{.0008} \\
\hline & & CG & 75 & 7.573 & 2.641 & & & & & & \\
\hline & $\mathrm{COK}$ & EG & 75 & 28.105 & 7.825 & \multirow{2}{*}{1.782} & \multirow{2}{*}{.184} & \multirow{2}{*}{148} & \multirow{2}{*}{-.567} & \multirow{2}{*}{.572} & \multirow{2}{*}{.0021} \\
\hline & & CG & 75 & 28.787 & 6.869 & & & & & & \\
\hline \multirow[t]{6}{*}{ Post-test } & CK & EG & 75 & 29.480 & 9.162 & \multirow{2}{*}{4.575} & \multirow{2}{*}{.034} & \multirow{2}{*}{148} & \multirow{2}{*}{11.795} & \multirow{2}{*}{$.000^{*}$} & \multirow{2}{*}{.48} \\
\hline & & CG & 75 & 15.207 & 5.482 & & & & & & \\
\hline & PK & EG & 75 & 13.150 & 6.811 & \multirow{2}{*}{8.897} & \multirow{2}{*}{.003} & \multirow{2}{*}{148} & \multirow{2}{*}{2.532} & \multirow{2}{*}{$.012^{*}$} & \multirow{2}{*}{.042} \\
\hline & & CG & 75 & 10.320 & 5.497 & & & & & & \\
\hline & COK & EG & 75 & 56.977 & 20.048 & \multirow{2}{*}{14.471} & \multirow{2}{*}{.000} & \multirow{2}{*}{148} & 0516 & $000 *$ & 38 \\
\hline & & CG & 75 & 33.167 & 9.238 & & & & 9.310 & .000 & .00 \\
\hline
\end{tabular}

*. This is a lower bound of true significance. a. Lilliefors Significance Correction

30. The central limit theorem stated that Field (2009); Saunders et al. (2009) as the sample size gets larger $(n>30)$, the more the distribution scores of the sample gets close to normality distribution. Normality of sampling distributions can be further verified and strengthened using Kolmogorov-Smirnov test statistics based on Table 3 .

The results shown in Table 3 indicate that the data on pre-test CK of the EG, COK of the CG; and post-test CK of the EG and CG, and COK of the CG were normally distributed. The results on the remaining distributions do not show normality. However, by the Central Limit Theorem as the sample size was large; the observed nonnormality sampling distributions can get close to normal.

Results of homogeneity of variances by Levene's test and the mean score difference by an independentsamples t-test and the corresponding effect size values measured by eta squared formula for both pre-and posttest on CK, PK and COK scores are shown in Table 4. The range of eta squared value is 0 to 1 (Cohen et al., 2007; Pallant, 2010). As Cohen et al. (2007); Pallant (2010) reported, Cohen (1988) provided guidelines to be used for the interpretation of eta squared value as $.01=$ small effect, .06 =moderate effect and .14 =strong effect.

By the Levene's test results shown in Table 4, the equality of variances for the dependent variables $C K, P K$ and $\mathrm{COK}$ in pre-test, and $\mathrm{CK}$ in post-test between EG and CG for the two populations were attained. The homogeneity of variances for $\mathrm{PK}$ and $\mathrm{COK}$ in post-test was not met. Further verification has made on it. According to Field (2009), when the variance for dependent variable of both populations are not equal, it should be interpreted based on the variance ratio (Hartley's $F_{\max }$ ) and the sample size. The reason is that large samples can be taken as a guarantee for Levene's test to be significant for small variation in group variances. The variance ratio value needs to be less than the critical values available in a table published by Hartley. To do this, the square root transformation was performed on post-test PK scores data. The variance ratio was found to be 1.53 . This variance ratio value for this case was reasonably less than the critical value for the associated sample size (75) per group. This implies that the variance was reasonably equal. Analogously, the log transformation was carried-out on post-test COK scores data. The variance ratio was found to be 1.92. This 

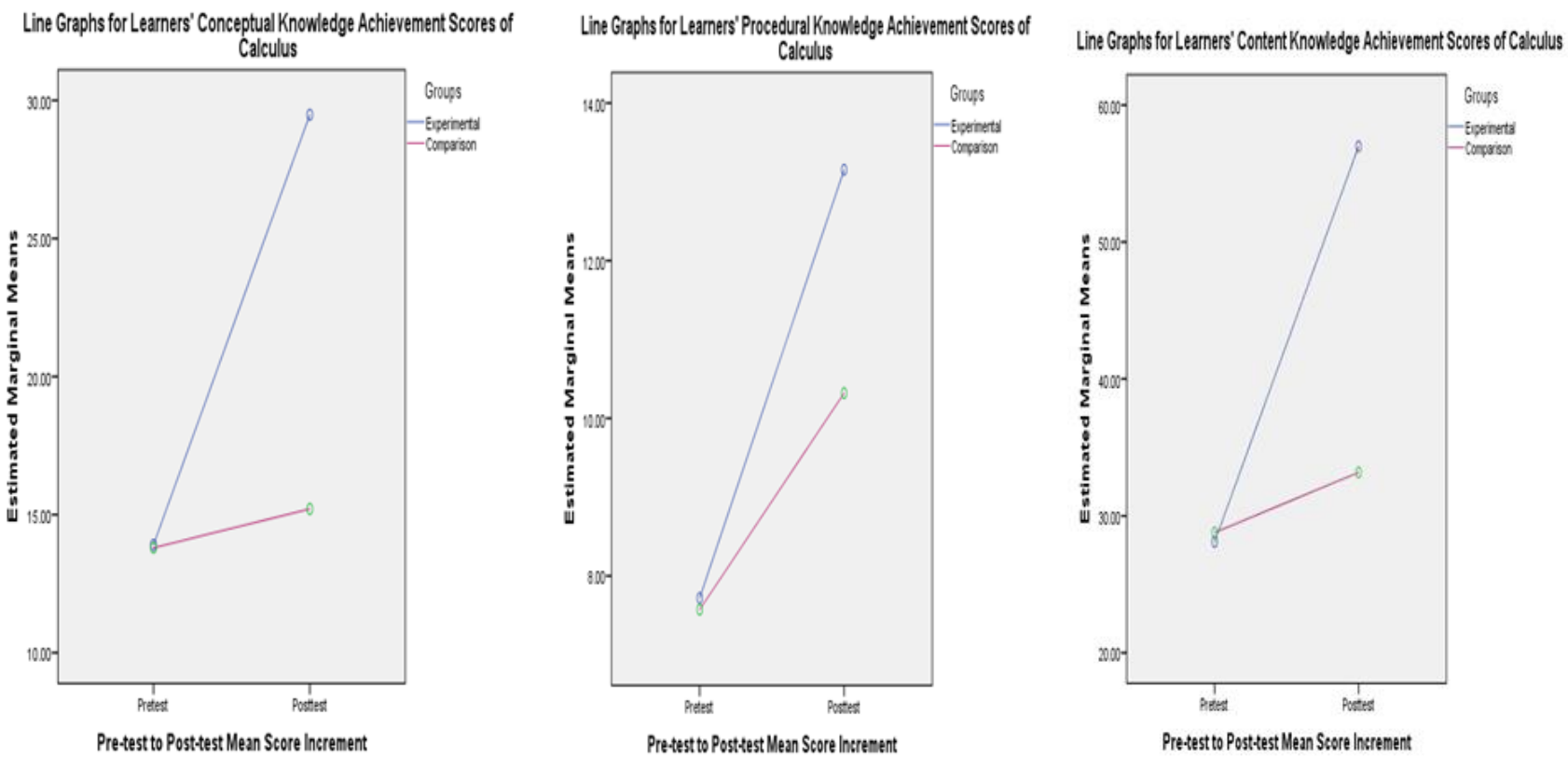

Figure 3. CK, PK, and COK Development through Pre-test to Post-test

variance ratio value was also reasonably less than the critical value. This implies that the variance was reasonably equal.

The effect size values of the mean score difference shown in Table 4 on pre-test CK, PK and COK between EG and CG represent very small effects (Cohen et al., 2007; Pallant, 2010). According to Cohen et al. (2005), these values imply that there was no statistically significant mean score difference. The data were in favour of the null hypotheses. Therefore, this result can be interpreted as at the pre-intervention, learners in both EG and CG had lower-order understanding of CK, PK and COK. However, they performed a bit better on PK because of prior procedural knowledge learning experiences gained through the traditional lecture method as compared to their CK achievement.

As to the post-intervention, the effect size values of the mean score difference shown in Table 4 on CK and COK between EG and CG reveal very strong effects while modest effect on PK. This implies that there was a statistically significant mean score differences between EG and CG on CK, PK and COK. The data were in favour of the alternative hypotheses. Therefore, these findings show that learners in the EG outperformed on the three knowledge domains of calculus compared to CG. This is the result of the influence of proper utilization of the blend of the active technology-based learning strategy (JCLGS) with Vygotsky's social constructivism learning theory in the mathematics laboratory and the conventional lecture method in the mainstream class by EG learners. Within EG, learners had performed the most on CK and COK domains while the least on PK domain of calculus. The CK domain attainment generated through the stimulus of the JCLGS with Vygotsky's social constructivism learning theory had highly influenced their COK development compared to PK improvement influence. These learners exhibited positive attitude towards the JCLGS and calculus in addition to their success on COK domain. The JCLGS stimulated EG to learn calculus concepts by their initiation, to be reflective, independent learners, socially active-interactive and to use GeoGebra appropriately as a learning visualization tool which might not be possible through black/white board.

Initial inspection of the extent of the mean score increment difference results on $\mathrm{CK}, \mathrm{PK}$ and $\mathrm{COK}$ through pre-test to post-test between EG and CG has been carried-out based on the line graphs shown in Figure 3.

The mean score increment for the EG on CK and COK domain shown in Figure 3 was substantial compared to the CG after the intervention while least on PK.

Whether the mean score increment through pre-test to post-test on CK, PK and COK between EG and CG in terms of the corresponding effect size values was significant or not has been further verified based on Two-Way ANOVA for repeated measures results shown in Table 5 .

The results shown in Table 5 reveal that the effects of pre-test and post-test conducted on both EG and CG on their CK, PK and COK development of calculus were statistically significant, respectively as $[F(1,148)=106.913$; $\left.\eta^{2}=.419 ; p<.01\right],\left[F(1,148)=7.328 ; \eta^{2}=.047 ; p<.01\right]$ and $\left[F(1,148)=80.917 ; \eta^{2}=.353 ; p<.01\right]$. The effect size values $\eta^{2}=.419$ on CK and $\eta^{2}=.353$ on COK development represent very large effects (Cohen et al., 2007; Pallant, 2010). The effect size value $\eta^{2}=.047$ on PK development lies between a small and moderate effect. Therefore, EG learners generated a large amount of $\mathrm{COK}$ of calculus as 
Table 5. ANOVA Results on CK, PK and COK Scores

\begin{tabular}{|c|c|c|c|c|c|c|}
\hline \multicolumn{7}{|c|}{ CK } \\
\hline Source of Variance & Sum of Squares & $\mathrm{df}$ & Mean Score & $\mathrm{F}$ & $\eta^{2}$ & $\mathrm{p}$ \\
\hline \multicolumn{7}{|c|}{ Between Groups } \\
\hline Group & 5406.008 & 1 & 5406.008 & 131.84 & .471 & $.000^{*}$ \\
\hline Error & 6068.467 & 148 & 41.003 & & & \\
\hline \multicolumn{7}{|c|}{ Within Groups } \\
\hline Pre-Post Test Measures & 3877.208 & 1 & 3877.208 & 110.158 & .427 & $.000^{*}$ \\
\hline Pre-Post test*Group & 3763.021 & 1 & 3763.021 & 106.913 & .419 & $.000^{*}$ \\
\hline Error & 5209.147 & 148 & 35.197 & & & \\
\hline \multicolumn{7}{|c|}{ PK } \\
\hline \multicolumn{7}{|c|}{ Between Groups } \\
\hline Group & 1254.607 & 1 & 1254.607 & 47.160 & .242 & $.000^{*}$ \\
\hline Error & 3937.247 & 148 & 26.603 & & & \\
\hline \multicolumn{7}{|c|}{ Within Groups } \\
\hline Pre-Post Test Measures & 166.507 & 1 & 166.507 & 9.015 & .057 & $.003^{*}$ \\
\hline Pre-Post Test*Group & 135.341 & 1 & 135.341 & 7.328 & .047 & $.008^{*}$ \\
\hline Error & 2733.527 & 148 & 18.470 & & & \\
\hline \multicolumn{7}{|c|}{ COK } \\
\hline \multicolumn{7}{|c|}{ Between Groups } \\
\hline Group & 20731.791 & 1 & 20731.791 & 130.500 & .469 & $.000^{*}$ \\
\hline Error & 23511.830 & 148 & 158.864 & & & \\
\hline \multicolumn{7}{|c|}{ Within Groups } \\
\hline Pre-Post Test Measures & 10030.614 & 1 & 10030.614 & 72.163 & .328 & $.000^{*}$ \\
\hline Pre-Post Test*Group & 11247.339 & 1 & 11247.339 & 80.917 & .353 & $.000^{*}$ \\
\hline Error & 20571.793 & 148 & 138.999 & & & \\
\hline
\end{tabular}

${ }^{*} \mathrm{p}<.01$

the result of the influence of their CK development through the stimulus of the JCLGS with Vygotsky's socio-cultural learning theory. The role of the innovative active technology-based learning strategy was significant for EG learners $\mathrm{CK}$ understanding in calculus. This implies the data was in favour of the alternative hypothesis $\mathrm{H}_{11}$. On the other hand, EG learners acquired a small amount of PK of calculus through the intervention which had impacted their COK improvement to a lesser extent.

\section{DISCUSSION}

This study employed a blended learning strategy combining traditional lecture method in mainstream class and the JCLGS in mathematics laboratory class which is different from the familiar blending strategy integrating mainstream (classroom) teaching and elearning system. The use of this innovative learning strategy that alerts educators to go beyond the traditional classroom instructional practices was proposed to alleviate learning difficulty of first year undergraduate mathematics and science learners in calculus concepts they experienced through the conventional method. It was also devised to reduce the challenge observed on educators' limited knowledge to the proposed learning strategy. In connection to this argument, Gambari and Yusuf (2016) indicated that learners' poor performance of the abstract concepts in science is due to teachers' use of poor instructional strategies and teacher-centred method.

In line with each research question/hypothesis, the pre-test findings reveal that all learners in both EG and CG except one learner scored below average mark in the calculus CK, PK and COK achievement test. Most experimental group learners' attitude towards the calculus learning was not positive in their opinion and feeling responses to a questionnaire using Likert-scale on attitudes. This implies that learners' negative attitude toward calculus is directly related to their poor performance of calculus and vice-versa. This agree with the findings in (Atanasova-Pachemska et al., 2015; Awang \& Hamid, 2015; Awang, Ilias, Che Hussain, \& Mokhtar, 2013; Eyyam \& Yaratan, 2014; Lin, Tseng, \& Chiang, 2016). Atanasova-Pachemska et al. (2015) stated that the less positive attitude learners towards the learning of mathematics have the less likely they achieve better and vice-versa.

In the post-test findings, most EG learners scored higher marks on CK, PK and COK in calculus classroom achievement test compared to CG. Most EG learners positively changed their opinion towards calculus. The use of the JCLGS for calculus learning was enjoyable and interesting for learners. They perceived learning calculus through the JCLGS as normal as other courses. This implies that the more positive attitude learners towards the learning of calculus have the more likely they perform better and vice-versa. The reason for 
experimental group learners' positively changed in attitude and highly performed in COK was most likely the influence of the CK development through the JCLGS using socio-cultural context learning theory on their calculus learning during the intervention. The other reason was the quality of the research instruments used to collect data which verified through suitable validity and reliability tests. Although the conventional method also affected CG in enhancing their COK through pretest to post-test over a semester as well, this was not comparable to that of the extent the JCLGS influenced experimental group. This was because during the intervention the experimental group learners were allowed to actively participate in their mathematics laboratory class to work with the learning activities prepared by the researcher using the JCLGS. Through this learning environment, they had learned concepts of calculus independently, collaboratively and interactively in their respective jigsaw groups and this ultimately influenced learners to be well-equipped with COK. Lin et al. (2016) by using the same design and similar blended learning strategy as the current study, they found-out that EG learners had been positively affected by this learning approach for their achievement and attitudinal change. All the results on learners' achievement in calculus through pre-test to post-test in this study agree with (Gambari \& Yusuf, 2016) findings on physics. The findings of this study confirmed the idea pointed-out by Mazana, Suero Montero, and Olifage (2019); Gambari and Yusuf (2016) as the instructional strategies that teachers use in classroom instruction and opinion of learners towards mathematics learning influence their power of retention and performance. The findings of this study are merely generalized to the whole freshman undergraduate mathematics and science learners in the College of Natural and Computational Sciences in two Ethiopian public universities who enrolled for calculus in 2017.

\section{CONCLUSION}

The intent to minimize learners' learning challenge of $\mathrm{CK}, \mathrm{PK}$ and COK in calculus by the proposed innovative learning strategy and to recommend professional development of educators' limited knowledge empowering them with such knowledge and skills involved in the strategy, intervention study was designed. It was also aspired in this same design to observe learners' attitudinal change towards intermediate calculus in learning it using the intervention. The intervention used was JCLGS. It applied to those learners in the treatment group. In contrast, learners in the comparison group were taught using the conventional method. As the result of the careful designing and implementation of the intervention by the researcher and data collectors/instructors and sharing of responsibility by research participants for their learning, it was found that the JCLGS substantially influenced learners' CK and COK. Learners understanding and interest towards calculus also increased. The impact of the JCLGS on PK development was the least as compared to CK and COK development.

However, compared to other related studies, the effect size values on CK and COK of this study were too big. The effect size value on PK was not that much different from other related studies. Keep in mind that learners' CK development had highly favoured their COK learning. Learners' use of the JCLGS in this study had largely improved their CK and COK development of various lessons of calculus. JCLGS had affected their interest and positively changed attitude towards intermediate calculus. The JCLGS had motivated them to visualize those abstract mathematical objects that might not be possible by conventional method through a black/whiteboard. It had taken place by numerical, symbolical, geometrical, algebraic/formula and calculus means representations of various abstract calculus concepts using GeoGebra. This is because as one of mathematics software packages GeoGebra has potential environments capable of representing abstract concepts in a variety of ways. During the intervention, learners were highly initiated to know all about other software packages used for teaching/learning mathematics. Thus, the contribution of JCLGS as educational technology on learners' CK and COK development was excellent and could be taken as the main finding.

\section{RECOMMENDATION}

One of the possible solutions this study provided using the stimulus JCLGS to overcome learners' learning challenges of CK, PK and COK in calculus was not perceived by the researcher as completely addressed. However, the researcher has a strong conviction that as he did his best in devising, processing and implementing the innovative technology-assisted learning strategy. Experimental group remarkably learned the learning activities of calculus prepared by him, exhibiting high interest toward calculus through the active technologyassisted learning strategy. In the course of this, the researcher had used his maximum energy to reduce any sort of flaws. Here, the researcher is not meant that the study was conducted without limitations. Rather, even one can take the research design itself was a limitation of the study. Keeping all these in mind, educators and scientific research community could consider the outcomes as input for their career. Specifically, university/college instructors and school teachers are advised to take this educational technology supported learning as a model of learning while presenting their lessons. Such learning environment will most likely make their learners to have interest and positive attitude towards calculus in particular and other mathematics and science courses in general. 


\section{REFERENCES}

Abed, A. Z., Sameer, S. A., Kasim, M. A., \& Othman, A. T. (2019). Predicting Effect Implementing the Jigsaw Strategy on the Academic Achievement of Students in Mathematics Classes. International Electronic Journal of Mathematics Education, 15(1), 17. https:// doi.org/10.29333/iejme/5940

Amineh, R. J., \& Asl, H. D. (2015). Review of constructivism and social constructivism. Journal of Social Sciences, Literature and Languages, 1(1), 9-16.

Arends, R. (1997). Classroom instruction and management. McGraw-Hill Companies.

Atanasova-Pacemska, T., Lazarova, L., Arsov, J., Pacemska, S. \& Trifunov, Z. (2015). Determination of the factors that form the students' attitude towards mathematics. Istraživanje matematičkog obrazovanja, 7(12), 1-8.

Awang, N., \& Hamid, N. N. A. (2015, October). Students attitude towards calculus subject: A case-study using structural equation modeling. In AIP Conference Proceedings,1682(1), 050012.1-050012.5). https:/ / doi.org/10.1063/1.4932503

Awang, N., Ilias, M. R., Che Hussain, W. S. E., \& Mokhtar, S. F. (2013, April). Students attitude towards calculus subject: Bumiputera case-study. In AIP Conference Proceedings, 1522(1), 392 -395. https:/ / doi.org/10.1063/1.4801151

Awang, T. S. \& Zakaria, E. (2012).The effects of integrating technology on students' conceptual and procedural understandings in integral calculus. Asian Social Science, 8(16), 8-16. https:/ / doi.org/10.5539/ass.v8n16p8

Ball, D. L., Thames, M. H., \& Phelps G. (2008). Content knowledge for teaching: What makes it special? Journal of Teacher Education, 59(5), 389-407. https: / / doi.org/10.1177/0022487108324554

Bezuidenhout, J. (2001). Limits and continuity: Some conceptions of first-year students. International Journal of Mathematical Education in Science and Technology, 32(4), 487-500. https:// doi.org/10.1080 / 00207390010022590

Boopathiraj, C. \& Chellamani, K. (2013). Analysis of test items on difficulty level and discrimination index in the test for research in education. International Journal of Social Science E Interdisciplinary Research, 2(2), 189-193.

Boz Yaman, B. (2019). A Multiple Case Study: What Happens in Peer Tutoring of Calculus Studies? International Journal of Education in Mathematics, Science and Technology, 7(1), 53-72. https://doi.org/10.18404/ijemst/328336

Castellan, C. M. (2010). Quantitative and qualitative research: A view for clarity. International journal of education, 2(2), 1-14. https://doi.org/10.5296/ ije.v2i2.446

Chinnappan, M., \& Forrester, T. (2014). Generating procedural and conceptual knowledge of fractions by pre-service teachers. Mathematics Education Research Journal, 26(4), 871-896. https://doi.org/ $10.1007 /$ s13394-014-0131-x

Cohen, L., Manion, L., \& Morrison, K. (2007). Approaches to qualitative data analysis. Research methods in education. https://doi.org/10.4324/ 9780203029053

Creswell, J. W., \& Creswell, J. D. (2019). Research design: Qualitative, quantitative, and mixed methods approaches. Sage publications. https://doi.org/ 10.1002/nha3.20258

DeVries, D. L. (1974). Teams-Games-Tournament in the Social Studies Classroom: Effects on Academic Achievement, Student Attitudes, Cognitive Beliefs, and Classroom Climate. Report Number 173. https:/ / doi.org/10.1037/e413442004-001

Dhage, J. R., Pawar, A. B., \& Patil, M. S. (2016). Effect of the Jigsaw-Based Cooperative Learning Method on Engineering Students. Journal of Engineering Education Transformations, 1-7. https://doi.org/ 10.16920/jeet/2016/v0i0/111630

Ding, L., \& Beichner, R. (2009). Approaches to data analysis of multiple-choice questions. Physical Review Special Topics-Physics Education Research, 5(2), 0201039(1-17). https://doi.org/10.1103/ PhysRevSTPER.5.020103

Engelbrecht, J., Harding, A., \& Potgieter, M. (2005). Undergraduate students' performance and confidence in procedural and conceptual mathematics. International Journal of Mathematical Education in Science and Technology, 36(7), 701-712. https:/ / doi.org/10.1080/00207390500271107

Eyyam, R. \& Yaratan, H. S. (2014). Impact of use of technology in mathematics lessons on student achievement and attitudes. Social Behavior and Personality: an international journal, 42(1), S31-S42. https: / / doi.org/10.2224/sbp.2014.42.0.S31

Field, A. (2009). Discovering Statistics Using SPSS (3rd Ed.). Sage publications.

Fraenkel, J. R., \& Wallen, N. E. (2009). How to design and evaluate research in education. New York: McGrowHill.

Gambari, I. A., \& Yusuf, M. O. (2016). Effects of Computer-Assisted Jigsaw II Cooperative Learning Strategy on Physics Achievement and Retention, Contemporary Educational Technology, 7(4), 352-367. https:/ / doi.org/10.30935/cedtech/6181

Gelo, O. C. G. (2012). On research methods and their philosophical assumptions: "raising the consciousness of researchers" again. Psychotherapie und Sozialwissenschaft, 14(2), 111-130. 
Graham, M., Milanowski, A., \& Miller, J. (2012). Measuring and Promoting Inter-Rater Agreement of Teacher and Principal Performance Ratings. Online Submission, ED532066, 1-33.

Gray, D. E. (2013). Doing research in the real world. Sage.

Green, S. B., \& Salkind, N, J. (2005). Using SPSS for Windows and Macintosh: Internal consistency estimates of reliability. Upper Saddle River, NJ: Pearson Prentice Hall.

Gull, F., \& Shehzad, S. (2015). Effects of Cooperative Learning on Students' Academic Achievement. Journal of Education and Learning, 9(3), 246-255. https://doi.org/10.11591/edulearn.v9i3.2071

Haapasalo, L., \& Kadijevich, D. (2000). Two types of mathematical knowledge and their relation. Journal for Mathematik-Didaktik, 21(2), 139-157. https:/ / doi.org/10.1007/BF03338914

Heibert, J., \& Lefevre, P. (1986). Conceptual and procedural knowledge in mathematics: An introductory analysis. Conceptual and procedural knowledge: The case of mathematics. Hillsdale, NJ, Erlbaum. https:/ / doi.org/10.4324/9780203063538

Huang, C. H. (2011). Investigating the attitudes toward calculus of engineering students in Taiwan. World Transactions on Engineering and Technology Education, 9(2), 80-85.

Imenda, S. (2014). Is there a conceptual difference between theoretical and conceptual frameworks? Journal of Social Sciences, 38(2), 185-195. https:/ / doi.org/10.1080/09718923.2014.11893249

Jaafar, R., \& Lin, Y. (2017). Assessment for Learning in the Calculus Classroom: A Proactive Approach to Engage Students in Active Learning. International Electronic Journal of Mathematics Education, 12(3), 503-520.

Kadijević, Đ. (1999). Conceptual tasks in mathematics education. The Teaching of Mathematics, 2(1), 59-64. Retrieved from https:/ / eudml.org/doc/255835

Kandemir, M. A., \& Demirbag-Keskin, P. (2019). Effect of Graphing Calculator Program Supported Problem Solving Instruction on Mathematical Achievement and Attitude. International Journal of Research in Education and Science, 5(1), 203-223. Retrieved from https://files.eric.ed.gov/fulltext/ EJ1197997.pdf

Kiliyanni, A. L., \& Sivaraman, S. (2016). The perceptionreality gap in financial literacy: Evidence from the most literate state in India. International Review of Economics Education, 23, 47-64. https://doi.org/ 10.1016/j.iree.2016.07.001

Liao, S. C., Hunt, E. A., \& Chen, W. (2010). Comparison between inter-rater reliability and inter-rater agreement in performance assessment. Annals Academy of Medicine Singapore, 39(8), 613-618.
Lin, Y. W., Tseng, C. L., \& Chiang, P. J. (2016). The effect of blended learning in mathematics course. EURASIA Journal of Mathematics, Science and Technology Education, 13(3), 741-770. https://doi.org/10.12973/eurasia.2017.00641a

Ma, J., Han, X., Yang, J., \& Cheng, J. (2015). Examining the necessary condition for engagement in an online learning environment based on learning analytics approach: The role of the instructor. The Internet and Higher Education, 24, 26-34. https:/ / doi.org/10.1016/j.iheduc.2014.09.005

Mahir, N. (2009). Conceptual and procedural performance of undergraduate students in integration. International Journal of Mathematical Education in Science and Technology, 40(2), 201-211. https:/ / doi.org/10.1080/002073908022213591

Mazana, Y. M., Suero Montero, C., \& Olifage, C. R. (2019). Investigating Students' Attitude towards Learning Mathematics. International Electronic Journal of Mathematics Education, 14(1), 207-231. https://doi.org/10.29333/iejme/3997

Mediawiki (n.d.). Retrieved from http://www.media wiki.org

Morgan, G. A., Leech, N. L., Gloeckner, G. W., \& Barrett, K. C. (2012). IBM SPSS for introductory statistics: Use and interpretation. Routledge. https://doi.org/ 10.4324/9780203127315

Mutambara, L. H. N., Tendere, J., \& Chagwiza, C. J. (2019). Exploring the Conceptual Understanding of the Quadratic Function Concept in Techers' Colleges in Zimbabwe. Eurasia Journal of Mathematics, Science and Technology Education, 16(2), 1-17, em1817. https://doi.org/10.29333/ejmste/ 112617

Orey, M. (2010). Emerging perspectives on learning, teaching and technology. North Charleston: CreateSpace.

Othman, Z. S., Tarmuji, N. H., \& Hilmi, Z. A. G. (2017, April). Students perception on the usage of PowerPoint in learning calculus. In AIP Conference Proceedings, 1830(1), 050005(1-7). AIP Publishing. https:/ / doi.org/10.1063/1.4980942

Pallant, J., \& Manual, S. S. (2010). A step by step guide to data analysis using SPSS. Berkshine UK: McGrawHill Education.

Resnick, L. B. (1987). The 1987 Presidential address learning in school and out. Educational researcher, 16(9), 13-54. https://doi.org/10.3102/0013189X 016009013

Rittle-Johnson, B., \& Alibali, M. W. (1999). Conceptual and procedural knowledge of mathematics: Does one lead to the other? Journal of educational psychology, 91(1), 175. https://doi.org/10.1037/ 0022-0663.91.1.175

Rittle-Johnson, B., \& Siegler, R. S. (1998). The relation between conceptual and procedural knowledge in 
learning mathematics: A review. https://doi.org/ 10.12691/education-5-3-12

Rittle-Johnson, B., Siegler, R. S. \& Alibali, M. W. (2001). Developing conceptual understanding and procedural skill in mathematics: An iterative process. Journal of educational psychology, 93(2), 346. https: / / doi.org/10.1037//0022-0663.93.2.346

Saha, R. A., Ayub, A. F. M., \& Tarmizi, R. A. (2010). The effects of GeoGebra on mathematics achievement: enlightening coordinate geometry learning. Procedia-Social and Behavioral Sciences, 8, 686-693. https://doi.org/10.1016/j.sbspro.2010.12.095

Saunders, M.N.K., Lewis, P., \& Thornhill, A. (2009). Research methods for business students (5 $5^{\text {th }}$ Ed.), Pearson education Limited, Harlow.

Sebsibe, A. S., \& Feza, N. N. (2019). Assessment of Students' Conceptual Knowledge in Limit of Functions. International Electronic Journal of Mathematics Education, 15(2), em0574. https:/ / doi.org/10.29333/iejme/6294

Şengül, S., \& Katranc1, Y. (2012). Teaching the Subject" Sets" with the 'Dissociation and Re-Association' (Jigsaw). International Online Journal of Educational Sciences, 4(1), 1-18.

Siyepu, S. (2013). The zone of proximal development in the learning of mathematics. South African Journal of Education, 33(2), 1-13. Art. \#714. https://doi.org/ 10.15700 / saje.v33n2a714

Star, J. R. (2005). Reconceptualizing procedural knowledge. Journal for research in mathematics education, 404-411. Retrieved from http:/ / www.jstor.org/stable/30034943

Star, J. R., \& Stylianides, G. J. (2013). Procedural and conceptual knowledge: exploring the gap between knowledge type and knowledge quality. Canadian Journal of Science, Mathematics and Technology Education, 13(2), 169-181. https:/ / doi.org/10.1080/ 14926156.2013.784828

Summit, R. A., \& Rickards, T. O. (2013). A constructivist approach to mathematics laboratory classes. In Proceedings of the 9th DELTA Conference on Teaching and Learning of Undergraduate Mathematics and Statisitcs (pp. 190-198).

Tran, V. D., \& Lewis, R. (2012). Effects of Cooperative Learning on Students at An Giang University in Vietnam. International Education Studies, 5(1), 86-99. https://doi.org/10.5539/ies.v5n1p86

Vygotsky, L. S. (1980). Mind in society: The development of higher psychological processes. Harvard university press. https:// doi.org/10.2307/j.ctvjf9vz4

Wertsch, J. V. (1985). Vygotsky and the social formation of mind. Harvard University Press. https://doi.org/ 10.1002/1520-6807(198910)26:4<423::AIDPITS2310260415>3.0

Yang, L.-N., \& Deng, J. (2005). Seminar: Training graduate students scientific research ability of the effective way. China's geological education, 3, 5-7.

Yilmaz, K. (2013). Comparison of quantitative and qualitative research traditions: Epistemological, theoretical, and methodological differences. European Journal of Education, 48(2), 31-325. https:// doi.org/10.1111/ejed.12014

Yimer, S. T., \& Feza, N. N. (2019). Learners' Conceptual Knowledge Development and Attitudinal Change towards Calculus Using Jigsaw Co-operative Learning Strategy Integrated with GeoGebra. International Electronic Journal of Mathematics Education, 15(1), 1-26, em0554. https:// doi.org/10.29333/iejme/5936

Yurniwati, Y., \& Soleh, D. A. (2019). Geometric Conceptual and Procedural Knowledge of Prospective Teachers. International Journal of Education and Pedagogy, 1(2), 106-115. https:/ / doi.org/10.23917/jramathedu.v3i2.6374

Zakaria, E. (2012). The effect of geogebra on students' conceptual and procedural knowledge of function. Indian Journal of Science and Technology, 5(12), 38023808. https:/ / doi.org/10.17485/ijst/2012/v5i12.12

Zulnaidi, H., \& Zakaria, E. (2012). The Effect of Using GeoGebra on Conceptual and Procedural Knowledge of High School Mathematics Students. The Journal Asian Social Science, 8(11), 102-106. https://doi.org/10.5539/ass.v8n11p102

\section{http://www.ejmste.com}

